\title{
Development and validation of a high performance liquid chromatographic method determination of Zidovudine encapsulated in PCL nanoparticles
}

\author{
Milena Cristina Ribeiro Souza Magalhães ${ }^{\mathrm{a}}$, , Alisson Samuel Portes Caldeira ${ }^{\mathrm{a}}$, Hanna de Sousa

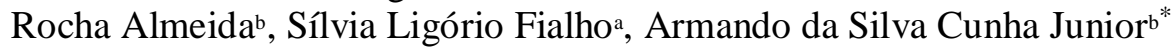 \\ a Pharmaceutical and Biotechnological Development, Fundação Ezequiel Dias, R. Conde Pereira Carneiro, 80, 30510- \\ 010, Belo Horizonte, Minas Gerais, Brazil \\ b School of Pharmacy, Federal University of Minas Gerais, Av. Presidente Antônio Carlos, 6627, 31270-901, Belo \\ Horizonte, Minas Gerais, Brazil. \\ Corresponding author e-mail: armando@farmacia.ufmg.br
}

\begin{abstract}
A reversed-phase high-performance liquid chromatographic (HPLC) method was developed and validated for the determination of encapsulation efficiency of zidovudine in nanoparticules. The method was carried out in isocratic mode using 0.040M sodium acetate: methanol: acetonitrile: glacial acetic acid (880:100:20:2) as mobile phase, a C8 column at $25^{\circ} \mathrm{C}$ and UV detection at $240 \mathrm{~nm}$. The method was linear $\left(\mathrm{r}^{2}>0.99\right)$ over the range of $25.0-150.0 \mu \mathrm{g} / \mathrm{mL}, \mathrm{precise}(\mathrm{RSD}<$ $5 \%$ ), accurate (recovery $=100.5 \%$ ), robust and selective. The validated HPLC-UV method can be successfully applied to determine the rate of zidovudine in nanoparticules.
\end{abstract}

Keywords: zidovudine; nanoparticle; polycaprolactone; HPLC; validation.

\section{Introduction}

About 36 million people are infected with the human immunodeficiency virus type-1 (HIV-1) worldwide (1). The majority of infected people live in the developing countries with limited treatment resources. Antiretroviral (AR) therapy has significantly reduced HIV-1 disease morbidity and improved life expectancy. Treatment failures due to the development of resistance and limited global access have prevented worldwide utility of AR therapy $(2,3)$. Dosing regimens that require multiple daily dosing with dietary considerations and AR side effects have compromised the achievement of long-term HIV-1 suppression in infected patients (4). Additionally, the use of AR requires a high level of commitment from the patient to prevent treatment failure due to resistance.

Zidovudine (Figure 1) was the first chemical substance which showed an anti-HIV activity, in 1985 (5). Nowadays zidovudine continues to be the first choice to the treatment of HIV-positive patients $(5,6)$. Zidovudine is a class 1 drug according the biopharmaceutical classification system (BCS), which is highly permeable and highly soluble. And $40 \%$ of this drug is lost in first pass metabolism (7).

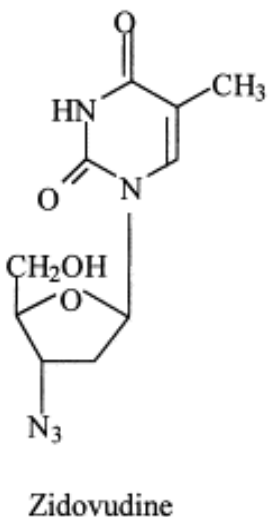

Figure 1 The structural formule of zidovudine.

Nanoparticles are stable, solid colloidal particles consisting of material ranging in size from 10 to $1,000 \mathrm{~nm}$. Drugs can be adsorbed on the particle surface, entrapped within the particle, or dissolved in the particle matrix $(8,9)$. Nanoparticles represent an interesting carrier system for the transport of antiviral drugs to monocyte/macrophage in an attempt to 
reduce the required dose, minimize toxicity and side effects, and improve the delivery of substances, which have insufficient intracellular uptake. Previous studies have demonstrated that AR can be fabricated inside nanoparticles as a drug delivery system $(8,9)$.

Zidovudine nanoparticles must be analyzed on quality parameters. For quantitative determination of zidovudine several analytical techniques have been used, such as thin layer chromatography (10), derivative ultraviolet spectrometry (11), capillary electrophoresis $(12,13)$, and high performance liquid chromatography (HPLC) with ultraviolet detection (14) or with mass detection $(15,16)$. A HPLC technique used to separate drugs based on hydrophobicity, is a good choice to determine the assay because it is a cheap, common and selective tool. There are official monographs in the United States Pharmacopeia for zidovudine determination in different pharmaceutical forms (17). However, none of these methods was evaluated to analyze zidovudine encapsulated in nanoparticles which should be simple and fast.

To assess the encapsulation efficiency zidovudine nanoparticles were analyzed by the HPLC technique, using an extremely simple and fast method that use small sample volume requirements and provides detection and quantitation of the drug.

\section{Experimental}

\section{Materials and reagents}

Zidovudine reference standard was purchased from Farmacopeia Brasileira (Brazil) (99.4\% of purity), Zidovudine related compound $\mathrm{C}$ was purchased from USP (USA) (MW 126.12). Polycaprolactone (MW 14,000) was purchased from Sigma Aldrich (Germany). Isopropyl myristate and sorbitan monooleate was obtained from Sigma Aldrich (Germany). Polysorbate 80 was purchased from MercK (Germany). Ultrapure water was obtained from a Milli- ${ }^{\circledR}$ apparatus (Millipore, USA). The others reagents used were HPLC or analytical grade.

\section{Instrumentation and analytical conditions}

The HPLC analysis were carried out on a Merck Hitachi LaChrom Elite chromatograph (Germany) which included a quaternary pump, autosampler, column oven and diode array detector (DAD). A Lichrocart@ column (125 x $4.0 \mathrm{~mm}$ i.d.; $5 \mu \mathrm{m}$ particle size) from Merck (Germany) was used and maintained at $25^{\circ} \mathrm{C}$. The injection volume was $10 \mu \mathrm{L}$ and detection was performed at $240 \mathrm{~nm}$. The mobile phase comprised of $0.040 \mathrm{M}$ sodium acetate: methanol: acetonitrile: glacial acetic acid (880:100:20:2) was used at the flow rate of 1.0 $\mathrm{mL} / \mathrm{min}$. Elma ultrasonic water bath (Germany), and Millipore filtration (USA) assembly were used in this study.

\section{Preparation of the zidovudine loaded nanoparticles}

The zidovudine loaded nanoparticles were prepared by the nanoprecipitation method, which involved mixing an organic phase in an aqueous phase (18). The required amounts of polymer and drug were dissolved in acetone with sorbitan monooleate and isopropyl myristate. The organic phase was gradually added to the aqueous phase containing polysorbate 80 using a small funnel under stirring. After, acetone was removed under low pressure through a rotary evaporator.

\section{Preparation of solutions}

Zidovudine standard solutions, Zidovudine related compound $\mathrm{C}$ solution, blank sample and blank matrix spiked with zidovudine were prepared. All the standard solutions were filtered through a $0.45 \mu \mathrm{m}$ filter (Sartorius, Germany). The concentration of zidovudine in each solution prepared is defined on the validation parameter description.

\section{Zidovudine standard solutions}

Zidovudine standard solutions at the concentrations of 75,100 and $125 \mu \mathrm{g} / \mathrm{mL}$ were prepared by weighing appropriate amount of zidovudine reference standard into a $25 \mathrm{~mL}$ volumetric flask and dissolving it in $18 \mathrm{~mL}$ water using an ultrasonic water bath. Water was added to complete the flask volume. The 
obtained solution was filtered using a $0.45 \mu \mathrm{m}$ filter and $10 \mathrm{~mL}$ of filtrated was transferred to a $100 \mathrm{~mL}$ volumetric flask. Water was added to complete the flask volume. $(\mathrm{n}=3$ for each level).

\section{Zidovudine related compound $C$ solution}

Zidovudine related compound $\mathrm{C}$ solution at a concentration of $2.0 \mu \mathrm{g} / \mathrm{mL}$ was prepared by weighing appropriate amount of zidovudine related compound $\mathrm{C}$ into a $25 \mathrm{~mL}$ volumetric flask and dissolving it in $18 \mathrm{~mL}$ water using an ultrasonic water bath. Water was added to complete the flask volume. The obtained solution was filtered in $0.45 \mu \mathrm{m}$ filter and 10 $\mathrm{mL}$ of filtrated was transferred to a volumetric flask $(100 \mathrm{~mL})$. Water was added to complete the flask volume. $(n=3)$.

\section{Blank matrix}

Nanoparticles without drug were prepared using the same method described in "Preparation of the zidovudine loaded nanoparticles" and served as blank matrix.

\section{Blank matrixes spiked with zidovudine}

The blank matrix spiked with zidovudine reference standard solutions at the concentrations of 75,100 and $125 \mu \mathrm{g} / \mathrm{mL}$ were prepared. An appropriate weight of blank matrix was transferred to a volumetric flask (25 $\mathrm{mL}$ ) containing an appropriate weight of zidovudine reference standard. Water $(18 \mathrm{~mL})$ was added to dissolve using an ultrasonic water bath. The obtained solution was filtered in a $0.45 \mu \mathrm{m}$ filter and $10 \mathrm{~mL}$ of filtrated was transferred to a volumetric flask $(100 \mathrm{~mL})$. Water was added to complete the flask volume $(n=3$ for each level).

\section{Method validation}

The method was validated for specificity, linearity, precision (repeatability and intermediated precision), limits of quantitation and detection, accuracy and robustness in accordance with standard procedure (19).

\section{Specificity}

Specificity was evaluated by comparing the following chromatographic peaks: zidovudine reference standard at the concentration of 100 $\mu \mathrm{g} / \mathrm{mL}$, zidovudine related compound $\mathrm{C}$ at the concentration of $2 \mu \mathrm{g} / \mathrm{mL}$, mobile phase, diluent and blank matrix spiked with zidovudine reference standard $(100 \mu \mathrm{g} / \mathrm{mL})$.

To achieve the method specificity, no peak, with the same retention time of zidovudine, was allowed. Additionally, spectral purity of zidovudine chromatographic peak was evaluated through UV spectra recorded by diode array detector (DAD).

\section{Stability of solution}

The stability of the solution of zidovudine was evaluated by analyzing the zidovudine standard solution at the concentration of 100 $\mu \mathrm{g} / \mathrm{mL}$ at the moment of the preparation and after 24 hours at refrigerator $\left(2\right.$ to $\left.8^{\circ} \mathrm{C}\right)$ and these areas of peaks were compared.

\section{Linearity}

The standard calibration curves were obtained from five zidovudine reference standard solutions, at the concentrations of 25 , $50,75,100,125$ and $150 \mu \mathrm{g} / \mathrm{mL}$. For each standard solution three independent replicates were evaluated. These assays were performed on two different days. The calibration curves obtained were assessed through residue analysis (outlier's test, normality, and homoscedascity and residue independence) and linear regression analysis was done by ordinal least squares method (20).

\section{Limit of detection (LOD) and limit of quantitation (LOQ)}

The method sensitivity was evaluated by determination of the lower quantitation limit (LOQ) and the detection limit (LOD). The LOD and LOQ were determined based on the signal to noise method and blank matrix analysis. The LOQ was defined as the lowest zidovudine concentration that could be determined with 
adequate precision and accuracy, whereas the LOD was defined as the lowest zidovudine concentration that could be detected but not quantified under the stated experimental conditions $(21,22)$. The blank matrix solutions were prepared in triplicate by two analists on two different days $(n=12)$.

The LOQ and LOD were calculated through equations 1 and 2, respectively:

LOQ $=10 \sigma / b($ Equation 1$)$

LOD $=3 \sigma / b$ (Equation 2)

where, $\sigma$ is the standard deviation of the response and $b$ is the slope of the calibration curve.

\section{Precision}

The intra-day precision (repeatability) was evaluated through analysis of the blank samples spiked with known amount of zidovudine performing 75,100 , and $125 \mu \mathrm{g} / \mathrm{mL}$ of the drug on the same day ( $\mathrm{n}=6$ for each concentration). Likewise, the inter-day precision (intermediate precision) was evaluated through the same sample preparation. However, they were assessed on two consecutive days ( $\mathrm{n}=12$ for each concentration). The precision was expressed as relative standard deviation (RSD) through the Analysis of the Variance (ANOVA).

\section{Accuracy}

The zidovudine standard solutions at the concentrations of 75,100 , and $125 \mu \mathrm{g} / \mathrm{mL}$ were prepared and analyzed. The solutions were prepared in triplicate by two analists $(\mathrm{n}=$ 18). Moreover, blank samples spiked with known amount of zidovudine performing 75, 100 , and $125 \mu \mathrm{g} / \mathrm{mL}$ of the drug were also prepared and analyzed. The blank samples spiked were prepared in triplicate by two analists $(n=12)$. The percent recovery of added zidovudine was calculated comparing responses of the blank samples with the responses of the reference standard zidovudine solutions at the same concentration levels.

\section{Robustness}

The method proposed by Youden e Steiner was carried out to evaluate the robustness (15). Seven analytical parameters were selected and investigated at two limits of variation relative to the nominal value. The upper limits were indicated by capital letters and the lower limits were indicated by lowercase letters in Table 1 . Eight chromatographic runs were performed following the experimental design of Youden and Steiner (Table 1) in order to determine the influence of each analytical parameter in the final result.

Table 1 Parameters, variation and factorial combination for robustness test studies.

\begin{tabular}{|c|c|c|c|c|c|c|c|c|c|c|}
\hline \multirow{2}{*}{$\begin{array}{l}\text { Analytical } \\
\text { parameter }\end{array}$} & \multirow{2}{*}{\multicolumn{2}{|c|}{ Value $(\mathbf{X} / \mathbf{x})$}} & \multicolumn{8}{|c|}{ Factorial combination } \\
\hline & & & 1 & 2 & 3 & 4 & 5 & 6 & 7 & 8 \\
\hline Column & $\begin{array}{c}\mathrm{A} \\
\mathrm{C} 18\end{array}$ & $\begin{array}{c}\mathrm{a} \\
\mathrm{C} 8\end{array}$ & A & A & A & A & $\mathrm{a}$ & a & a & a \\
\hline $\begin{array}{l}\text { Wavelength } \\
(\mathrm{nm})\end{array}$ & $\begin{array}{c}\text { B } \\
238\end{array}$ & $\begin{array}{c}\mathrm{b} \\
242\end{array}$ & B & B & $\mathrm{b}$ & $\mathrm{b}$ & B & B & $\mathrm{b}$ & $\mathrm{b}$ \\
\hline $\begin{array}{l}\text { Mobile phase } \\
\text { flow rate } \\
(\mathrm{mL} / \mathrm{min})\end{array}$ & $\begin{array}{c}\mathrm{C} \\
0.8\end{array}$ & $\begin{array}{c}\mathrm{c} \\
1.2\end{array}$ & $\mathrm{C}$ & c & $\mathrm{C}$ & $\mathrm{c}$ & $\mathrm{C}$ & $\mathrm{c}$ & $\mathrm{C}$ & $\mathrm{c}$ \\
\hline $\begin{array}{l}\text { Proportion of } \\
\text { the mobile } \\
\text { phase }(0.040 \mathrm{M} \\
\text { sodium acetate/ } \\
\text { methanol/ } \\
\text { acetonitrile/ } \\
\text { glacial acetic } \\
\text { acid) }\end{array}$ & $\begin{array}{c}\text { D } \\
870: 105: 2: 25\end{array}$ & $\begin{array}{c}\mathrm{d} \\
890: 95: 2: 15\end{array}$ & $\mathrm{D}$ & $\mathrm{D}$ & d & d & d & d & $\mathrm{D}$ & $\mathrm{D}$ \\
\hline $\begin{array}{l}\text { Injection } \\
\text { volume }(\mu \mathrm{L})\end{array}$ & $\begin{array}{l}\mathrm{E} \\
8\end{array}$ & $\begin{array}{c}\mathrm{e} \\
12\end{array}$ & $\mathrm{E}$ & $\mathrm{e}$ & E & $\mathrm{e}$ & $\mathrm{e}$ & E & e & $\mathrm{E}$ \\
\hline $\begin{array}{l}\text { Temperature of } \\
\text { sample } \\
\text { compartment } \\
\left({ }^{\circ} \mathrm{C}\right) \\
\end{array}$ & $\begin{array}{c}\mathrm{F} \\
23\end{array}$ & $\begin{array}{c}\mathrm{f} \\
27\end{array}$ & $\mathrm{~F}$ & $\mathrm{f}$ & $\mathrm{f}$ & $\mathrm{F}$ & $\mathrm{F}$ & f & f & $\mathrm{F}$ \\
\hline Filter unit & $\begin{array}{c}\mathrm{G} \\
\text { cellulose }\end{array}$ & $\stackrel{\mathrm{g}}{\mathrm{PVDF}^{*}}$ & G & $\mathrm{g}$ & $\mathrm{g}$ & G & $\mathrm{g}$ & G & G & $\mathrm{g}$ \\
\hline Results & & & $\mathrm{s}$ & $\mathrm{t}$ & $\mathrm{u}$ & $\mathrm{v}$ & $\mathrm{w}$ & $\mathrm{x}$ & $\mathrm{y}$ & $\mathrm{z}$ \\
\hline
\end{tabular}

The zidovudine standard solution at the concentration of $100 \mu \mathrm{g} / \mathrm{mL}$ and the blank sample spiked with zidovudine at the concentration of $100 \mu \mathrm{g} / \mathrm{mL}$ were injected three times for each combination. Then, the recovery of the spiked zidovudine was calculated.

The results of each experiment were represented by letters ranging from $\mathrm{s}$ to $\mathrm{z}$ (Table 1 ). To estimate the effect of each variation on the final result, the difference between the mean of the four values corresponding to the capital letters (upper limits) and the mean of the four values corresponding to the lowercase letters (lower limits) was calculated (23). Thus, to evaluate the influence, for example, on 
wavelength in the final result of the analysis, Equation 3 was used as given below:

Effect $G / g=\frac{(s+v+x+y)}{4}-\frac{(t+u+w+z)}{4}$

(Equation 3)

The effect of the analytical parameter was considered to be significant if the value of the difference was greater than $(S \sqrt{2})$, where, $S$ is the standard deviation of the eight results (24).

\section{Application of the validated HPLC-UV method for determination of Encapsulation efficiency of nanoparticles}

Polycaprolactone nanoparticles $(600 \mu \mathrm{L})$ were dissolved in $3 \mathrm{~mL}$ of acetonitrile and transferred to a volumetric flask $(10 \mathrm{~mL})(\mathrm{n}=$ $3)$. Water was added to complete the flask volume. In ultra centrifugal filter units $2 \mathrm{~mL}$ of polycaprolactone nanoparticles were added and centrifuged at $9,000 \mathrm{rpm}$ for 30 minutes. Thereafter, $600 \mu \mathrm{L}$ of the filtrated were transferred to a volumetric flask $(10 \mathrm{~mL})(\mathrm{n}=3)$. Water was added to complete the flask volume. The amount of zidovudine in both cases was determined by the validated high performance liquid chromatographic method described before. The percentage of zidovudine loaded in nanocapsules was calculated by the equation 4 : ( $\mathrm{T}$ zidovudine $-\mathrm{F}$ zidovudine) $\mathrm{x} 100=\%$ zidovudine loaded (Equation 4)

where "T zidovudine" is the concentration of total zidovudine and " $F$ zidovudine" is the concentration of free zidovudine.

\section{Results and Discussion}

\section{Optimization of the chromatographic conditions}

In this study, an HPLC-UV method was optimized and validated for determination of zidovudine encapsulated in polycaprolactone nanoparticles.

The optimal absorption wavelength for zidovudine detection was chosen based on the higher detector response for this drug. Therefore, the absorption wavelength for detection was set on $240 \mathrm{~nm}$.

Different proportions of $0.040 \mathrm{M}$ sodium acetate: methanol: acetonitrile: glacial acetic acid were tested in order to define the appropriate mobile phase. The selected mobile phase proportion was consisted of a solution $0.040 \mathrm{M}$ sodium acetate: methanol: acetonitrile: glacial acetic acid (880:100:20:2). It was observed that increasing the amount of acetonitrile in mobile phase the zidovudine retention time was reduced due to more affinity between the drug and the mobile phase.

\section{Method validation}

The specificity of the method was investigated and it was observed that zidovudine and zidovudine related compound C eluted approximately at 12 and 2 minutes respectively (Figure $2 \mathrm{a}$ and $2 \mathrm{~b}$ ). There was no peak on the same retention times of zidovudine and zidovudine related compound $\mathrm{C}$ during the analysis of blank sample (Figure 2c). The chromatographic peak of zidovudine was completely resolved and none of substances from mobile phase or diluent presented the same zidovudine retention time of zidovudine. Additionally, peak purity higher than $99.0 \%$ was obtained for the drug in the chromatograms of zidovudine spiked in blank sample, indicating that other components did not coelute with the drug peak. According to obtained results, the method showed specificity for zidovudine in the presence of the polycaprolactone nanoparticles.

The stability of the solution of zidovudine was evaluated by analyzing the area of peaks of zidovudine standard solution at the concentration of $100 \mu \mathrm{g} / \mathrm{mL}$ at the moment of the preparation and after 24 hours under refrigeration $\left(2\right.$ to $\left.8^{\circ} \mathrm{C}\right)$. This difference of teor was $0.82 \%$ which showed that zidovudine solution to be continued stable after 24 hours after of the preparation under refrigeration. 

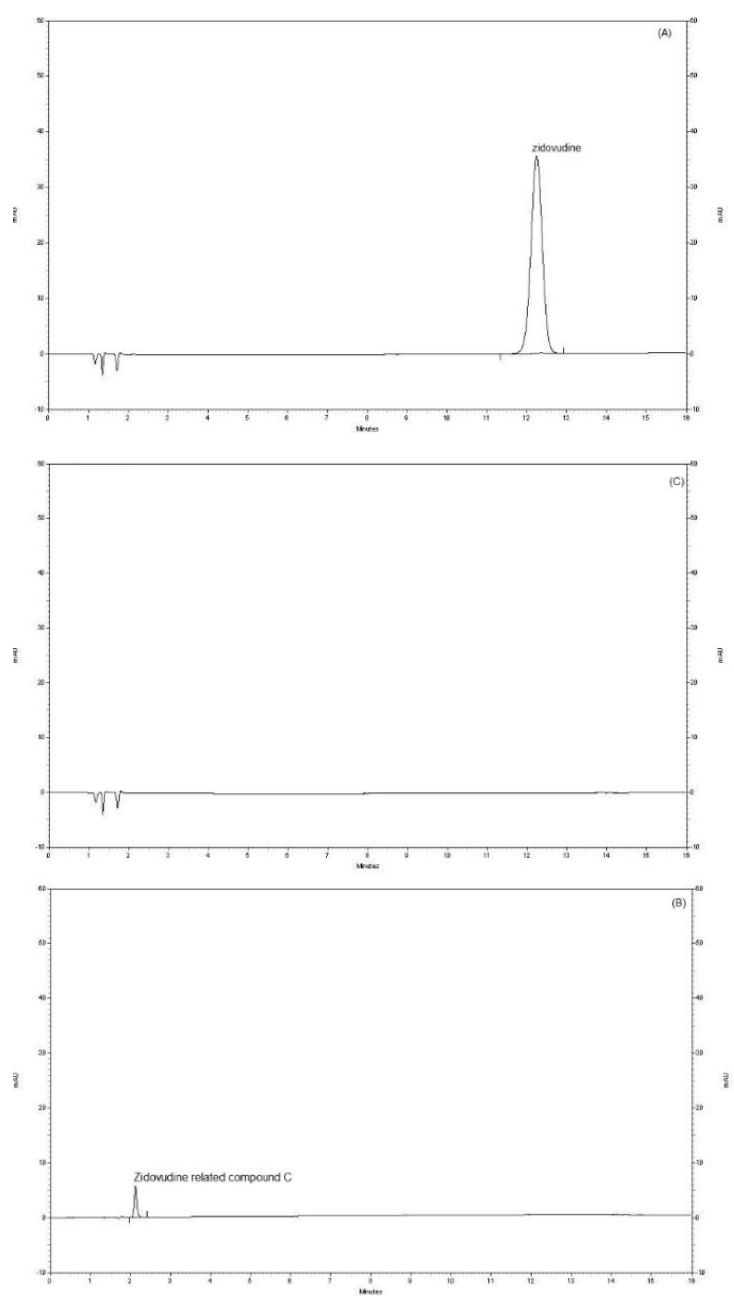

Figure 2 (A) Chromatogram of zidovudine at the concentration of $100 \mu \mathrm{g} / \mathrm{mL}$. (B) Chromatogram of Zidovudine related compound $\mathrm{C}$ at the concentration of 2.0 $\mu \mathrm{g} / \mathrm{mL}$. (C) Chromatogram of Blank matrix. Chromatographic conditions: $\mathrm{C}_{8}$ column $125 \mathrm{~mm} \times 4.0 \mathrm{~mm}$ at $25^{\circ} \mathrm{C} ; 0.040 \mathrm{M}$ sodium acetate: methanol: acetonitrile: glacial acetic acid (880:100:20:2); $1 \mathrm{~mL} / \mathrm{min}$ of flow rate; wavelength of $240 \mathrm{~nm}$.

A calibration curve relating concentration of the drug to area of peaks was plotted and the obtained data were subjected to linear regression analysis by ordinal least square method. The calibration curve was linear over the range of $25 \mu \mathrm{g} / \mathrm{mL}$ to $150 \mu \mathrm{g} / \mathrm{mL}$. The linearity could be defined by the following equation " $y=30000 x-9172.2 "$, where $y$ and $x$ are the area and the concentration $(\mu \mathrm{g} / \mathrm{mL})$, respectively. The significance of the calibration curve intercept was tested and this parameter was not statistically significant $(\mathrm{p}>0.05)$, which can be considered, consequently, that the curve passes through the origin (25). The correlation coefficient (r) was higher than 0.99 , showing highly significant correlation between concentration and peak area. The determination coefficient $\left(\mathrm{R}^{2}\right)$ of the calibration curve was 0.9999 , implying that $99.99 \%$ of total variance of the peak areas was explained by the varying zidovudine concentration. Finally, the linear model proved to be adequate since the residues followed a normal distribution pattern and were independent, the homoscedasticity could be observed and the lack of fit was not significant. The LOD was $0.9156 \mu \mathrm{g} / \mathrm{mL}$ and this concentration displayed a signal-to-noise ratio of $3: 1$. The LOQ was $2.535 \mu \mathrm{g} / \mathrm{mL}$ and this concentration displayed a signal-to-noise ratio of 10:1.

The repeatability (intra-day precision) and intermediated precision (inter-day precision) were expressed as the relative standard deviation (RSD) of a series of measures of different concentrations of zidovudine incorporated into blank solutions. The data obtained for precision were summarized in Table 2. The RSD values were lower than $5 \%$ for all levels of concentrations tested, thus indicating appropriate intra and inter-day precision (26).

Table 2 Mean content of zidovudine in the intra-day and inter-day precision.

\begin{tabular}{llcc}
\hline & Mean & $\begin{array}{c}\text { Intra-day } \\
\text { precision }\end{array}$ & $\begin{array}{l}\text { Inter-day } \\
\text { precision }\end{array}$ \\
\cline { 3 - 4 } $\begin{array}{l}\text { concentration } \\
(\mu \mathrm{g} / \mathrm{mL})\end{array}$ & content & RSD & RSD \\
\hline 75 & 101.66 & 0.25 & 0.33 \\
\hline 100 & 101.16 & 0.50 & 0.60 \\
\hline 125 & 100.50 & 1.01 & 1.19 \\
\hline
\end{tabular}

The accuracy of the HPLC-UV method was expressed as the percent of recovery of zidovudine spiked in the blank sample. The recovery ranged from $101.16 \%$ to $101.66 \%$, as demonstrated on Table 3. All the recovery values were between $80.0 \%$ and $110.0 \%$ of the theoretical concentration, confirming the accuracy of the proposed method.

Table 3 Percent recovery of zidovudine spiked in blank matrix.

\begin{tabular}{ccc}
\hline $\begin{array}{c}\text { Zidovudine } \\
\text { concentration }(\boldsymbol{\mu g} / \mathbf{m L})\end{array}$ & Percent recovery & $\boldsymbol{R S D}$ \\
\hline 75 & 101.66 & 0.32 \\
\hline 100 & 101.16 & 0.59 \\
\hline 125 & 100.50 & 1.16 \\
\hline
\end{tabular}


The results obtained on the robustness test are shown in Table 4. The HPLC-UV method appears to be robust regarding all the variables analyzed, as the difference between results obtained in differents conditions were lower than the critical value for all analytical parameters studied. During the assays, the zidovudine retention time was not significantly changed and peak symmetry was maintained. However, it could be noted that the column and mobile phase proportion were the factors that had more influence on method performance. Thus, these analytical parameters should be carefully controlled.

Table 4a Effects of the analytical parameters in the percent of recovery of zidovudine.

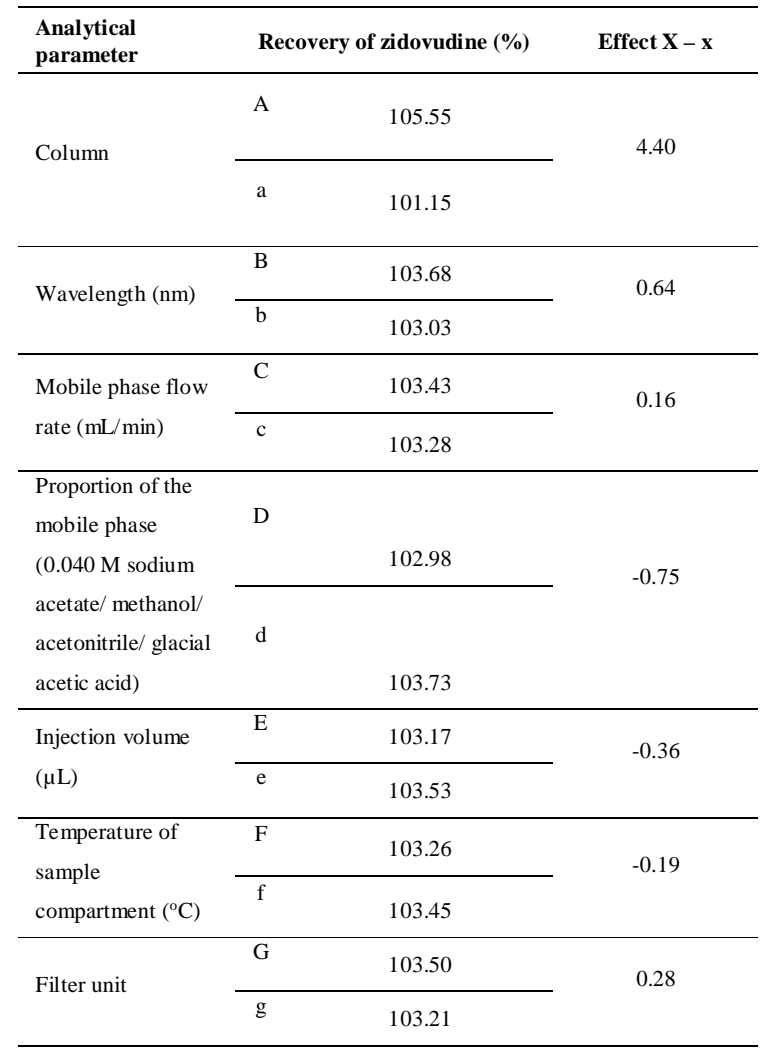

\section{Application of the validated HPLC-UV method for determination of zidovudine} encapsulated in nanoparticles

The zidovudine standard solution and the zidovudine nanoparticles samples were prepared, analyzed and quantified by applying the validated HPLC-UV method. The concentration of free zidovudine and total zidovudine were obtained and the percentage of encapsulated zidovudine was determinated. The encapsulated zidovudine was equal to $58.23 \%(58.23 \mu \mathrm{g} / \mathrm{mL})(\mathrm{n}=5)$. The relative standard deviation for five sample replicates was $3.4 \%$.

\section{Conclusions}

An HPLC-UV method was developed for determining the encapsulation efficiency of zidovudine in nanoparticles. This chromatographic method was considered simple and rapid, since the preparation of the samples did not involve complex and prolonged processes. Furthermore, the HPLC-UV method was validated in terms of selectivity, stability, linearity, limits of quantitation and detection, precision, accuracy and robustness. Finally, it provided unequivocal determination of the amount of zidovudine in nanoparticule formulation which may be applied to stability or quality control.

\section{Acknowledgements}

The authors wish to thank CNPq/MCT and FAPEMIG (Brazil) for financial support.

\section{References}

1. Piot, P.; Bartos, M.; Ghys, P.D.; Walker N.; Schwartlander B. Nature. 2001, 410, 968973.

2. Chen, R.Y.; Westfall, A.O.; Raper, J.L.; Cloud G.A.; Chatham A.K.; Acosta E.P.; et al. AIDS Trd Hum Retroviruses. 2002, 18, 900-916.

3. Chulamokha, L.; DeSimone, J.A.; Ponerantz, R.J.; J. Neurovirol. 2005, 11, 7680.

4. Fellay, J.; Boubaker, K.; Ledergerber, B.; Bernasconi, E.; Furrer, H.; Battegay, M., et al. Lancet. 2001, 358, 1322-1327.

5. De Souza, M.V.N. Acta Farm. Bonaerense. 2005, 24, 291-9. 
6. Perry, C.M.; Faulds, D. Drugs. 1997, 53, 657-80.

7. Lindenberg, M.; Kopp, S.; Dressman, J. B. European Journal of Pharmaceutics and Biopharmaceutics, 2004, 58, 265-278.

8. Dou, H.; Destache, C.J.; Morehead, J.R.; Mosley, R.L.; Boska, M.D.; Kingsley, J.; et al. Blood. 2006, 108, 2827-2835.

9. Shah, L.K; Amiji, M.M. Pharm Res. 2006, 23, 2638-2645.

10. Kaale, E.; Risha, P.; Reich, E.; Layloff, T.P. J AOAC Int. 2010, 93(6), 1836-43.

11. Ramakanth, R. D.; et al. International Journal of PharmTech Research. 2012, 4, 1, 311-314.

12. Alnouti, Y., White, C.A., Bartlett, M.G. Biomed Chromatogr. 2004, 18(8), 523-31.

13. Pereira, E. A.; Micke, G.A.; Tavares, M. F. M. Journal of Chromatography A. 2005, 1091, 1-2, 169-176

14. Kusuma, S. L., et al. International journal of research in pharmacy and chemistry. 2011, 1,3, 677-680

15. Moore, J. D.; Valette, G.; Darque, A.; Zhou, X.J.; Sommadossi, J. Journal of the American Society for Mass Spectrometry. 2000, 11, 1134-1143

16. Estrela, R. de C. E.; Salvadori, M. C.; Suarez-Kurtz, G. Rapid Communications in Mass Spectrometry. 2004, 18, 10, 11471155

17. The United States Pharmacopeia, 35th ed. 2012. United States Pharmacopoeial Convention: Rockville.

18. Fessi, H.; Puiseiux, F.; Devissaguet, J-P.; Ammoury, N.; Benita, S. Int. J. Pharm. 1989, 55, 1.
19. International Conference on Harmonisation of Technical Requirements for Registration of Pharmaceuticals for Human Use; Validation of Analytical Procedures: Text and Methodology, 2005.

20. Souza, S.V.C.; Junqueira, R.G.; Anal. Chim. Acta. 2005, 552, 25-35.

21. Causon, R.; J Chromatogr B. 1997, 689, 175-180.

22. Santana, F.J.M.; Cesarino, E.J.; Bonato, P.S. J Chromatogr B. 2004, 809, 351-356.

23. Youden, W.J.; Steiner, E.H. 1975. Statistical manual of AOAC - Association of Official Analytical Chemistry. Washington: AOAC.

24. Bedregal, P.; Torres, B.; Ubillús, M.; Mendoza, P.; Montoya, E.; J Radioanal Nucl Chem. 2008, 278, 801-806.

25. Saliba, J.B.; Silva-Cunha A.J.; Gomes, E.C.L.; Mansur, H.S.; Da Silva, G.R.; Quim. Nova. 2011, 34(1), 140-144.

26. Brazil. Agência Nacional de Vigilância Sanitária. 2003. Resolução RE n899 de 29 de Maio de 2003. Guia para validação de métodos analíticos e bioanalíticos, Diário Oficial da União: Brasília. 